\title{
Avaliação Das Condições Higiênico-Sanitárias de Uma Indústria de Gelados Comestíveis de Belém (Pa)
}

Elisa Cristina Andrade Neves (I), Consuelo Lúcia Sousa De Lima (I), Lúcia De Fátima Henriques Lourenço (I), Rafaela Maracajá Colaço

(I), Andreia Luiz Uchôa (I)

(I) UFPA - Universidade Federal do Pará (Rua Augusto Corrêa, 01 - Guamá. CEP 66075-110. Caixa postal 479. )

\section{Resumo}

Para garantir a produção de alimentos seguros, entre eles os gelados comestíveis como o sorvete, e manter a competitividade desses produtos no mercado, tornam-se necessário que as empresas implantem sistemas ou programas de qualidade, como as Boas Práticas de Fabricação (BPF), objetivando manutenção, armazenamento e comercialização do produto. $\mathrm{O}$ consumidor não associa que o sorvete ingerido em momentos de lazer e descontração possa apresentar riscos de natureza microbiológica, pois este julga que a baixa temperatura assegure sua inocuidade. Mas, como a resistência de micro-organismos ao congelamento é muito variável, se houver alguma contaminação da matéria-prima ou no momento do processamento e eles forem resistentes, podem permanecer viáveis e serem ingeridos pelos consumidores, podendo vir a causar toxinfecções, o que é preocupante, pois a comercialização de sorvetes na cidade de Belém (PA) está em constante expansão. O objetivo do trabalho foi avaliar as condições higiênico-sanitárias de uma indústria de gelados comestíveis de Belém (PA). A avaliação foi realizada através da aplicação em três vistorias da Lista de Verificação, elaborada de acordo com a RDC 267, de 25/09/2003, e análises microbiológicas em 54 amostras de sorvetes coletadas durante as vistorias, swab em 2 equipamentos, 3 utensílios e nas mãos de 4 manipuladores e da água da torneira e do filtro. Foram realizadas análises de Coliformes a $45^{\circ} \mathrm{C}$, Salmonella spp, Estafilococos coagulase + e

\footnotetext{
Referência:

Elisa Cristina Andrade Neves, Consuelo Lúcia Sousa De Lima, Lúcia De Fátima Henriques Lourenço, Rafaela Maracajá Colaço, Andreia Luiz Uchôa. Avaliação Das Condições Higiênico-Sanitárias de Uma Indústria de Gelados Comestíveis de Belém (Pa). In: Anais do 12을 Congresso Latinoamericano de Microbiologia e Higiene de Alimentos MICROAL 2014 [= Blucher Food Science Proceedings, num.1, vol.1]. São Paulo: Editora Blucher, 2014. DOI 10.5151/foodsci-microal-106
} 
contagem de bactérias mesófilas e psicrófilas utilizando a metodologia do Compendium of Methods for the Microbiological Examination Foods. Os resultados referentes a avaliação das condições higiênico-sanitárias indicaram uma média da porcentagem de itens conformes de 54,30\%, $83,70 \%, 63,04 \%$ nas $1^{\mathrm{a}}, 2^{\mathrm{a}}$ e $3^{\mathrm{a}}$ vistorias, respectivamente. Para Coliformes a $45^{\circ} \mathrm{C}$ foram observados que $77,70 \%, 11,10 \%$ e $38,80 \%$ das amostras coletadas na $1^{\mathrm{a}}, 2^{\mathrm{a}}$ e $3^{\mathrm{a}}$ vistorias estavam fora do padrão exigido pela legislação brasileira, respectivamente, bem como a contagem de bactérias psicrófilas: $66,60 \%, 16,60 \%, 55,50 \%$, respectivamente. Não foi encontrado em nenhuma amostra presença de Salmonella sppe E.coag. +. Todas as amostras de água estavam $100 \%$ dentro do padrão, mas os resultados das análises de swab indicaram que $100 \%$ estavam fora dos padrões. Portanto, sugerem-se maiores cuidados nas BPF, principalmente na higiene pessoal dos manipuladores, ambiental e na sanitização dos equipamentos e utensílios utilizados.

Palavras-Chave: Boas Práticas de Fabricação, Sorvete, Microbiologia Agência de Fomento: 